\title{
Distribution of Aspergillus Section Flavi among Field Soils from the Four Agroecological Zones of the Republic of Bénin, West Africa
}

\author{
K. F. Cardwell, International Institute of Tropical Agriculture, B.P. 08-0932, Cotonou, Bénin, and U.S. Department \\ of Agriculture, ARS, SRRC, P.O. Box 19687, New Orleans, LA 70179; and P. J. Cotty, U.S. Department of Agri- \\ culture, ARS, SRRC, P.O. Box 19687, New Orleans, LA 70179
}

\begin{abstract}
Cardwell, K. F., and Cotty, P. J. 2002. Distribution of Aspergillus section Flavi among field soils from the four agroecological zones of the Republic of Bénin, West Africa. Plant Dis. 86:434439.

Certain members of Aspergillus section Flavi produce carcinogenic and immunotoxic metabolites called aflatoxins. These fungi perennate in soils and infect maize grain in the field and in storage. The distribution of Aspergillus section Flavi across the four different agroecologies of Bénin Republic was determined. The four agroecological zones range from humid equatorial tropics in the south to the dry savanna near the Sahara desert in the north. Soil samples collected in 1994 to 1996 from 44 different maize fields in Bénin were assayed over 3 years (88 samples total) for fungi in Aspergillus section Flavi. All soils tested contained A. flavus. Isolates $(1,454$ total) were collected by dilution plate from the soils and existed in populations ranging from $<10$ to $>200 \mathrm{CFU} / \mathrm{g}$ of soil. CFU counts did not differ from year to year or change significantly with cropping systems within a zone, but differed significantly among zones. Incidence of A. flavus strain isolations varied from south to north, with greater number of CFU of L strain isolates in southern latitudes and higher numbers of CFU of S strain isolates found in the north. The L strain isolates occurred in 81 of 88 samples, whereas S strain isolates were in only 41 of 88 soil samples. Of $96 \mathrm{~L}$ strain isolates tested, $44 \%$ produced aflatoxins. Only B toxins were produced, and toxigenic isolates averaged over $100 \mu \mathrm{g}$ of aflatoxin $\mathrm{B}_{1}$ per $70 \mathrm{ml}$ of fermentation medium ( 1.4 ppm). All S strain isolates produced both $\mathrm{B}$ and $\mathrm{G}$ aflatoxins, averaging over 557 $\mu \mathrm{g}$ of aflatoxin $\mathrm{B}_{1}$ per $70 \mathrm{ml}(8 \mathrm{ppm})$ and $197 \mu \mathrm{g}$ of aflatoxin $\mathrm{G}_{1}$ per $70 \mathrm{ml}$ of fermentation medium $(2.8 \mathrm{ppm})$. A. parasiticus and A. tamarii were present in less than $10 \%$ of the fields and were not associated with any particular agroecological zone.
\end{abstract}

Maize has been adopted as a primary staple human food in Africa. In parts of West Africa, it is consumed up to three times a day and is used as weaning food for babies $(1,21)$. Maize is vulnerable to degradation by mycotoxic fungi, but in the developing world and in sub-Saharan Africa in particular, official monitoring of mycotoxin contamination levels is rare. In West Africa, 98\% of people test serologically positive for aflatoxin exposure (32), and in Bénin Republic and Nigeria high concentrations of aflatoxins have been found in pre- and postharvest maize $(15,27,30,31)$. Aflatoxin is one of the most potent natural toxins that people may consume without knowledge of potential health impacts $(2,4)$.

Corresponding author: K. F. Cardwell

E-mail: Kcardwell@srrc.ars.usda.gov

Accepted for publication 21 September 2001.

Publication no. D-2002-0215-01R

This article is in the public domain and not copyrightable. It may be freely reprinted with customary crediting of the source. The American Phytopathological Society, 2002.
All aflatoxin producing fungi are contained within Aspergillus section Flavi. Fungal isolates within section Flavi vary widely in aflatoxin producing ability $(10,13,17)$. Interest in this variability has increased because of recent suggestions that atoxigenic strains of $A$. flavus and $A$. parasiticus might be applied to agricultural fields in order to reduce the risk of aflatoxin contamination $(5,9,12)$. The species most commonly implicated in contamination events, A. flavus, can be divided into two strains on the basis of morphological, physiological, and genetic criteria $(3,7)$. Typical or L strain isolates vary widely in aflatoxin producing ability, and a significant percent of L strain isolates are atoxigenic (produce no aflatoxins). S strain isolates have a tendency to produce greater quantities of smaller sclerotia than L strain isolates. $\mathrm{S}$ strain isolates also produce more aflatoxin than $\mathrm{L}$ strain isolates, and atoxigenic $\mathrm{S}$ strain isolates are rare $(7,10,17)$. The $S$ strain has been further divided into $S_{B}$ isolates that produce only $B$ aflatoxins and $S_{B G}$ isolates that produce both $B$ and $G$ aflatoxins $(11,25)$. Initial comparison of S strain isolates from West Africa and North America revealed that only $\mathrm{S}_{\mathrm{B}}$ isolates occurred in North America, whereas in West Africa only $S_{B G}$ occurred $(11,16)$. Description of the variability within Aspergillus section Flavi across the distinct agroecological zones of West Africa would facilitate efforts to define the etiology of aflatoxin contamination in that region. The current study looks at the distribution and toxigenicity of species and strains within Aspergillus section Flavi across four agroecological zones in Bénin Republic.

\section{MATERIALS AND METHODS}

Survey methods. Surveys were conducted from 1994 to 1996 to evaluate distribution of Aspergillus section Flavi in cultivated soils immediately prior to harvest in Bénin Republic. Samples were collected from each of the four agroecological zones of Bénin (Fig. 1). The coastal savanna (CS) (south of $7.5^{\circ}$ latitude) has two growing seasons (April to July and September to November), average rainfall between 1,300 and $1,500 \mathrm{~mm}$, and mean temperatures from 25 and $35^{\circ} \mathrm{C}$. The southern Guinea savanna (SGS) (between 7.5 and $8.5^{\circ}$ latitude) has the same bimodal seasonal pattern as the CS, rainfall ranging from 1,000 to $1,300 \mathrm{~mm}$, and temperature maxima from 26 to $38^{\circ} \mathrm{C}$. The northern Guinea savanna (NGS) (8.5 to $10.5^{\circ}$ latitude) is characterized by one growing season (April to September), average rainfall of 1,000 to $1,100 \mathrm{~mm}$, and temperature maxima varying from 28 to $40^{\circ} \mathrm{C}$. The northernmost Sudan savanna (SS) also has one growing season (May to September), rainfall between 900 and $1,000 \mathrm{~mm}$, and temperature maxima of 28 to $45^{\circ} \mathrm{C}$ (Fig. 1). Thus, rains decrease and temperatures increase with increasing latitude with CS southernmost, followed by SGS, then NGS, and SS northernmost. Cropping systems were recorded in each field (Table 1).

Maize fields were selected arbitrarily in each agroecological zone by the criteria that the maize had cobs (dough stage or older) and that they were no closer that 5 $\mathrm{km}$ from the previous field. Soils were collected from 40 fields in 1994, 22 fields in 1995, and 26 fields in 1996. Across the years, 22 fields were sampled more than once to assess the fungal population over time relative to the cropping system. A 
total of 22 fields were sampled from the CS, 29 from the SGS, 22 from the NGS, and 15 from the SS.

In each field, five subsamples were randomly taken within each of four quadrants with a probe to a depth of 23 to $30 \mathrm{~cm}$, and the 20 subsamples were pooled, oven-dried for 5 days at $40^{\circ} \mathrm{C}$, and stored in sealed plastic bags at room temperature (22 to $26^{\circ} \mathrm{C}$ ) until used. Soil $\mathrm{pH}$ was measured in $\mathrm{H}_{2} \mathrm{O}$ (20\% soil, wt/vol).

Strain isolation and CFU quantitation. CFU were estimated by dilution plate technique on Modified Rose Bengal Agar (MRBA), a selective medium for Aspergillus section Flavi (8). Aspergillus section Flavi colonies were identified by characteristic growth pattern, retention of rose Bengal in mycelia, and production of characteristic conidiophores after 3 days on MRBA (8). All Aspergillus section Flavi colonies were transferred to $5 / 2$ agar $(5 \%$ V8 juice and 2\% agar, $\mathrm{pH} 5.2$ ). After 5 days incubation (unilluminated, $31^{\circ} \mathrm{C}$ ) on $5 / 2$ agar, isolates were classified into species and strain by observing colony characteristics and, when necessary, with microscopic verification of conidial morphology as previously described (8). Several 3-mm plugs of sporulating culture were transferred to 4-dram vials containing $5 \mathrm{ml}$ of sterile distilled $\mathrm{H}_{2} \mathrm{O}$. These conidial suspensions were stored for further study at $8^{\circ} \mathrm{C}$.

Aflatoxin production from soil isolates. In order to determine relative frequency of toxic to nontoxic strain distribution across the country, a subset of 2 to $3 \mathrm{~L}$ strain isolates was selected randomly from each soil sample in 1994. Aflatoxin production of 96 of these L strain isolates was measured in the liquid medium of Adye and Matales (A\&M), as previously described $(8,20)$. To assess variance in toxin production among strains, aflatoxin production by 10 additional $\mathrm{L}$ strain isolates was compared with $10 \mathrm{~S}$ strain isolates in three replicates of fermentation per isolate in modified A\&M medium. A pair of one $\mathrm{L}$ strain and one $S$ strain isolate was randomly selected from the isolate conidial suspensions from each of 10 fields. In order to detect the $\mathrm{S}_{\mathrm{BG}}$ phenotype, fermentations were performed in A\&M medium containing $22.5 \mathrm{mM}$ urea as the sole nitrogen source (11). Fermentations were replicated three times. Erlenmeyer flasks (250 $\mathrm{ml}$ ) containing $70 \mathrm{ml}$ of medium were inoculated with $100 \mu$ l of conidial suspension $(5,000$ to 7,000 conidia). Flasks were incubated at $30^{\circ} \mathrm{C}$ in the dark on an orbital shaker $(150 \mathrm{rpm})$ for 5 days, after which 70 $\mathrm{ml}$ of acetone was added to each flask to lyse fungal cells and extract the aflatoxins from the mycelium.

Culture filtrates containing $50 \%$ acetone (vol/vol) were filtered through Whatman No. 4 filter paper. One hundred milliliters of filtrate was added with an equal volume of water to a 250-ml separatory funnel, and the solution was extracted twice with 25 $\mathrm{ml}$ of methylene chloride. Extracts were filtered through $50 \mathrm{~g}$ of anhydrous sodium sulfate to remove residual water, and the sodium sulfate was rinsed with an additional $25 \mathrm{ml}$ of methylene chloride after filtration. The methylene chloride fractions were combined and dried in a fume hood. The residue was redissolved in $4 \mathrm{ml}$ of methylene chloride and either diluted or concentrated to allow accurate densitometry. Extracts and aflatoxin standards were separated on thin-layer chromatography plates (silica gel 60, $250 \mathrm{~mm}$ ) by development with diethyl ether-methanol-water $(96: 3: 1)$ (29). Aflatoxins were quantified using a scanning densitometer (model cs930, Shimadzu Scientific Instruments, Inc., Tokyo) (24).

Data analysis. All analyses were done with SAS version 2000, SAS Institute, Cary, NC. Pearson correlation coefficients were generated to assess relationships of ecological and biological variables. A general linear models (GLM) procedure was used to analyze variance of the main and

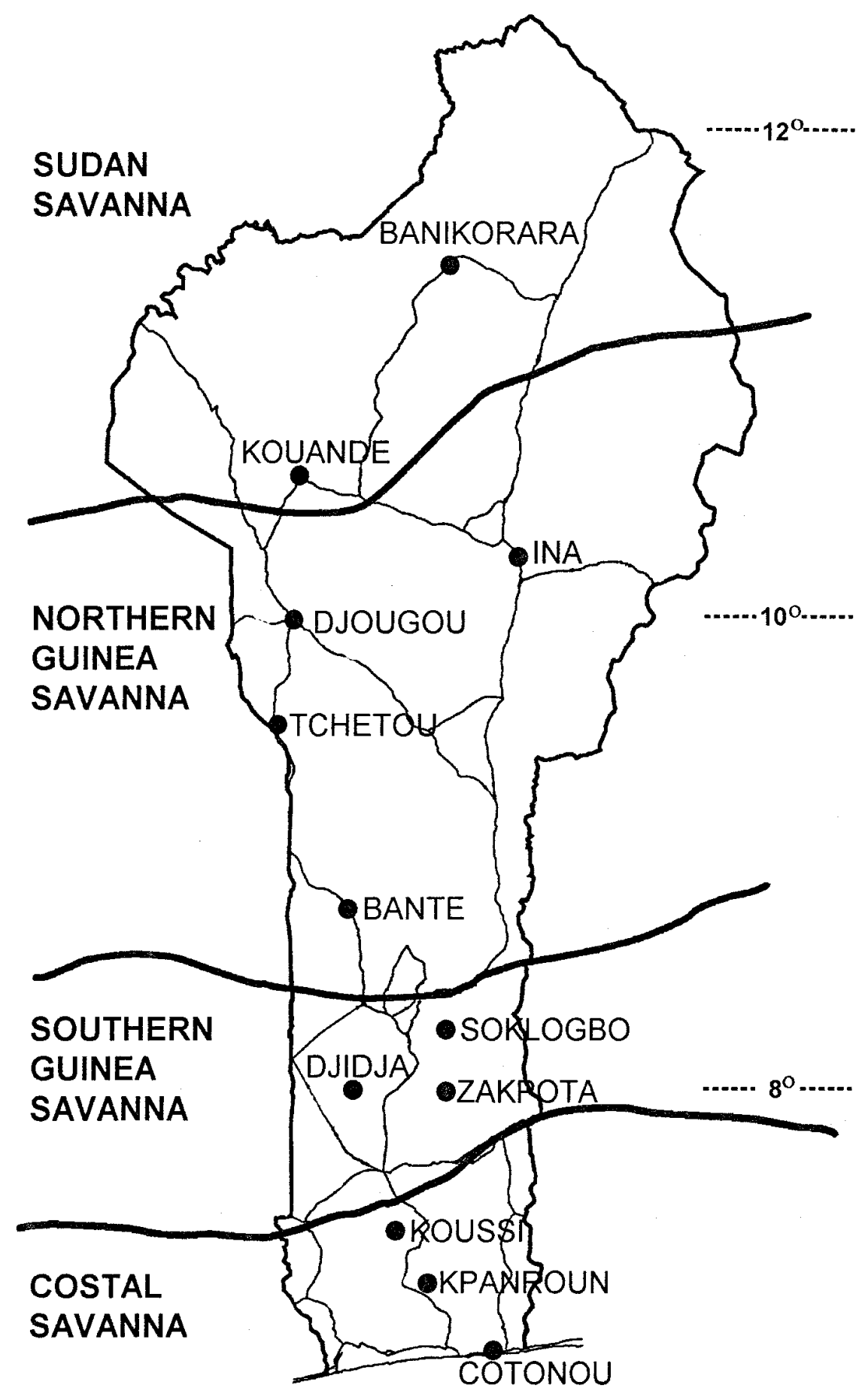

Fig. 1. Map of Bénin Republic with agroecological zones and villages where soil samples were collected. 
interactive effects of location and crop system over time on CFU of A. flavus, and least significant differences (LSD) means analyses were performed on $\log _{10}$ (count $+1)$ and arcsine square root $(\%)$ transformed data. Zones and crop systems were treated as class variables.

\section{RESULTS}

Aspergillus section Flavi was detected in soil from each of the 88 field samples. $A$. flavus was predominant $(90 \%$ of section Flavi), followed by $A$. tamarii (7\%) and $A$. parasiticus $(2 \%)$. One percent of the iso- lates could not be assigned to a previously described species. A total of 1,454 section Flavi colonies were transferred from MRBA to 5/2 agar. Of the A. flavus, $25 \%$ were $\mathrm{S}$ strain isolates. Although A. flavus was detected in all 88 fields, L strain isolates were detected in all but 7 , and $\mathrm{S}$ strain isolates were found in only 41 fields. Of 96 $\mathrm{L}$ strain isolates tested, 42 were positive for aflatoxin $B_{1}$ production, with the $B_{1^{-}}$ positive isolates producing just over $100 \mu \mathrm{g}$ per $70 \mathrm{ml}$ of fermentation medium (1.4 ppm) (data not shown). No L strain isolate produced aflatoxin $\mathrm{G}_{1}$. Five A. parasiticus isolates were tested for aflatoxin production in liquid medium, and all produced over $1,000 \mu \mathrm{g}$ of aflatoxin $\mathrm{B}_{1}(14.3 \mathrm{ppm})$ and over $150 \mu \mathrm{g}$ of aflatoxin $\mathrm{G}_{1}$ per $70 \mathrm{ml}$ of fermentation medium (2.1 ppm) (data not shown). All $10 \mathrm{~S}$ strain isolates tested produced both $\mathrm{B}$ and $\mathrm{G}$ aflatoxins averaging over $557 \mu \mathrm{g}$ of aflatoxin $\mathrm{B}_{1}(8.0 \mathrm{ppm})$ and $197 \mu \mathrm{g}$ of aflatoxin $\mathrm{G}_{1}$ per $70 \mathrm{ml}$ of fermentation medium (2.9 ppm) (Table 1). Of the $10 \mathrm{~L}$ strain isolates tested in triplicate, no $\mathrm{G}$ aflatoxins were produced and only $50 \%$ produced aflatoxin $\mathrm{B}_{1}$. The average $B_{1}$ aflatoxin produced by $L$ strain iso-

Table 1. Aflatoxin ${ }^{\mathrm{x}}$ production ( $\mu \mathrm{g}$ per $70 \mathrm{ml}$ of fermentation medium) by selected isolates of Aspergillus flavus $\mathrm{S}$ and $\mathrm{L}$ strains in liquid fermentation

\begin{tabular}{|c|c|c|c|c|c|c|c|}
\hline Isolate $^{y}$ & Strain & $\mathbf{B}_{1}$ & $\mathbf{G}_{1}$ & ISOLATE & Strain & $\mathbf{B}_{1}$ & $\mathbf{G}_{1}$ \\
\hline BN005K & $\mathrm{S}$ & 149.05 & 103.90 & $\mathrm{BN} 005 \mathrm{~F}$ & $\mathrm{~L}$ & 24.06 & 0.00 \\
\hline BN027S & $\mathrm{S}$ & 434.20 & 87.02 & BN027A & $\bar{L}$ & 399.00 & 0.00 \\
\hline BN031L & $\mathrm{S}$ & 25.67 & 12.90 & BN031R & $\mathrm{L}$ & 0.00 & 0.00 \\
\hline BN033L & $S$ & 83.41 & 39.06 & BN033A & $\mathrm{L}$ & 0.00 & 0.00 \\
\hline BN035E & $\mathrm{S}$ & 132.08 & 75.53 & BN035I & $\mathrm{L}$ & 0.00 & 0.00 \\
\hline BN039A & $\mathrm{S}$ & $1,443.36$ & 496.63 & BN039B & $\mathrm{L}$ & 164.72 & 0.00 \\
\hline BN047C & $\mathrm{S}$ & 981.38 & 758.66 & BN047A & $\mathrm{L}$ & 0.00 & 0.00 \\
\hline BN053G & $\mathrm{S}$ & 34.86 & 24.61 & BN053N & $\mathrm{L}$ & 90.00 & 0.00 \\
\hline BN059A & $\mathrm{S}$ & $1,821.75$ & 222.70 & BN059K & $\mathrm{L}$ & 0.00 & 0.00 \\
\hline BN066G & $\mathrm{S}$ & 458.72 & 149.26 & BN066A & $\mathrm{L}$ & 36.97 & 0.00 \\
\hline Mean $^{z}$ & S & $556.45 \mathrm{a}$ & $197.03 \mathrm{a}$ & & $\mathrm{L}$ & $62.48 \mathrm{~b}$ & $0.00 \mathrm{~b}$ \\
\hline
\end{tabular}

${ }^{\mathrm{x}}$ Means of three replications.

y Paired isolate accessions were selected for demonstration purposes only. Isolate identification, BN = Bénin, 000-060 refers to field number, letters A to T refer to isolate within field.

${ }^{\mathrm{z}}$ LSD mean comparison at $\alpha=0.5$ compares aflatoxin $\mathrm{B}_{1} \mathrm{~S}$ versus $\mathrm{L}$ strains and aflatoxin $\mathrm{G}_{1} \mathrm{~S}$ versus $\mathrm{L}$ strains. Mean quantities of both aflatoxin $\mathrm{B}_{1}$ and $\mathrm{G}_{1}$ produced by $\mathrm{S}$ strain isolates differ significantly from those produced by $\mathrm{L}$ strain isolates.

Table 2. Cropping system, soil pH, and CFU per g of soil of Aspergillus section Flavi of fields near selected villages across four ecozones in Bénin during 1994 to 1996

\begin{tabular}{|c|c|c|c|c|c|c|}
\hline Village & Crop system & Year & Zone $^{\mathrm{a}}$ & pH & $\%$ A. flavus & $\mathrm{CFU} / \mathrm{g}^{\mathrm{b}}$ \\
\hline \multirow[t]{2}{*}{ Kouande } & Maize + cowpea & 1994 & SS & 6.5 & 100 & 11 \\
\hline & Maize + sorghum & 1995 & & & 100 & 91 \\
\hline \multirow[t]{3}{*}{ Banikora } & Maize sole & 1994 & SS & 7.2 & 100 & 15 \\
\hline & Maize + cotton & 1995 & & & 100 & 6 \\
\hline & Maize + cowpea & 1996 & & & 40 & 32 \\
\hline \multirow[t]{2}{*}{ Glazoue } & Maize + groundnut & 1995 & NGS & 7.2 & 87 & 33 \\
\hline & Cotton & 1996 & & & 100 & 140 \\
\hline \multirow[t]{2}{*}{ Banté } & Maize sole & 1995 & NGS & 6.8 & 100 & 16 \\
\hline & Maize + cotton & 1996 & & & 95 & 48 \\
\hline \multirow[t]{2}{*}{ Guessou Sud } & Maize & 1995 & NGS & 5.7 & 71 & 15 \\
\hline & Maize + sorghum & 1996 & & & 100 & 77 \\
\hline \multirow[t]{2}{*}{ Ina } & Maize & 1995 & NGS & 6.4 & 100 & 184 \\
\hline & Maize & 1996 & & & 100 & 56 \\
\hline \multirow[t]{2}{*}{ Tchetou } & Maize & 1995 & NGS & 6.4 & 100 & 1,262 \\
\hline & Soybean & 1996 & & & 100 & 61 \\
\hline \multirow[t]{3}{*}{ Djidja(1) } & Maize sole & 1994 & SGS & 7.5 & 86 & 111 \\
\hline & Maize + groundnut & 1995 & & & 91 & 50 \\
\hline & Maize + cowpea & 1996 & & & 100 & 15 \\
\hline \multirow[t]{2}{*}{ Soklogbo } & Maize + cotton & 1995 & SGS & 6.5 & 93 & 19 \\
\hline & Maize + cassava & 1996 & & & 95 & 123 \\
\hline \multirow[t]{2}{*}{ Zakpota } & Maize + groundnut & 1994 & SGS & 7.5 & 95 & 320 \\
\hline & Maize & 1995 & & & 91 & 190 \\
\hline \multirow[t]{3}{*}{ Houngomè } & Maize + groundnut & 1994 & SGS & 6.6 & 100 & 230 \\
\hline & Maize & 1995 & & & 100 & 75 \\
\hline & Maize + cowpea & 1996 & & & 100 & 39 \\
\hline \multirow[t]{2}{*}{ Koussi } & Maize + groundnut & 1995 & $\mathrm{CS}$ & 6.9 & 100 & 7,868 \\
\hline & Maize + cassava & 1996 & & & 92 & 61 \\
\hline \multirow[t]{3}{*}{ Kpanroun } & Maize + cassava & 1994 & $\mathrm{CS}$ & 7.2 & 100 & 82 \\
\hline & Maize + cassava & 1995 & & & 100 & 128 \\
\hline & Maize + cassava & 1996 & & & 100 & 101 \\
\hline \multirow[t]{3}{*}{ Avegame } & Maize + cassava & 1994 & $\mathrm{CS}$ & 7.8 & 95 & 4,271 \\
\hline & Maize sole & 1995 & & & 100 & 113 \\
\hline & Maize sole & 1996 & & & 95 & 203 \\
\hline
\end{tabular}

y From north to south: SS = Sudan, NGS = northern Guinea, SGS = southern Guinea, and CS = coastal savannas.

${ }^{\mathrm{z}} \log _{10}(\mathrm{CFU})$ used in analysis, untransformed data presented. LSD means analysis revealed no differences between crop systems. 
lates, $62.5 \mu \mathrm{g}$ per $70 \mathrm{ml}(0.9 \mathrm{ppm})$, was significantly lower than the production by the $\mathrm{S}$ strain isolates (Table 1).

Significant differences among years were not seen in the quantity of propagules (CFU) per gram of soil or incidence of particular section Flavi species (Tables 2 and 3). Mean CFU, percent A. flavus and percent $A$. parasiticus were not significantly correlated with either zone or crop system (Table 2). However, incidence of S strain isolates differed significantly among zones, and incidence of $A$. tamarii differed significantly among both zones and crop systems (Table 3 ).

Maize was found intercropped (grown simultaneously in the same field) with several other crops. Maize with cassava was predominant in the south (Coastal Savanna), maize with groundnut or cotton was more frequent in the Guinea savannas, and maize with cotton, sorghum, or cow- pea was common in the Sudan savanna (Table 2). Fields having intercropped maize with cotton, groundnut, and/or sorghum had significantly higher CFU counts of A. tamarii ( $\mathrm{n}=5$, data not shown), resulting in a significant $F$ value in a GLM analysis of variance for crop system effect on the quantity of $A$. tamarii in soils (Table 3 ) that could not be explained by effect of agroecological zone (Table 4). There was no apparent effect of crop system on $A$. flavus or $A$. parasiticus counts when differences due to zone were accounted for (crop system analyzed as a nested variable within zone).

Soil $\mathrm{pH}$ decreased significantly from south to north in Bénin, ranging from an average of 6.98 in the CS to 6.55 in the SS (Table 4). Mean CFU of A. flavus per gram of soil was extremely variable, ranging from 6 to 28,000. CFU counts were significantly higher in the SGS than the SS
(Table 4). A. flavus, A. parasiticus, and A. tamarii were found distributed across all agroecological zones, but none were significantly associated with any particular zone (Table 4). The $\mathrm{S}$ strain isolates of $A$. flavus were significantly more frequent in northern latitudes, while L strain isolates were significantly more frequent in southern latitudes (Tables 4 and 5). Incidence of the S strain was negatively correlated, and incidence of the $\mathrm{L}$ strain was positively correlated, with soil $\mathrm{pH}$. However, this was not a strong effect and was confounded with latitude (Table 5).

\section{DISCUSSION}

Aspergillus section Flavi is widely distributed across Bénin. Studies from Israel and North America show similar frequencies of A. flavus, and in those regions $A$. parasiticus occurs in frequencies similar to those found in the current study

Table 3. Effect of crop system (cropsys), agroecological zone, and year on mean CFU per g of soily, and percent Aspergillus section Flaviz ${ }^{\mathrm{z}}$ group isolates in soils across Bénin

\begin{tabular}{|c|c|c|c|c|c|c|c|c|c|c|c|}
\hline & \multirow[b]{2}{*}{ df } & \multicolumn{2}{|c|}{ Mean CFU } & \multicolumn{2}{|c|}{ \% A. flavus } & \multicolumn{2}{|c|}{$\%$ S strain } & \multicolumn{2}{|c|}{$\%$ A.parasiticus } & \multicolumn{2}{|c|}{$\%$ A. tamarii } \\
\hline & & $F$ value & $P>F$ & $F$ value & $P>F$ & $F$ value & $P>F$ & $F$ value & $P>F$ & $F$ value & $P>F$ \\
\hline Year & 2 & 0.04 & 0.84 & 3.43 & 0.07 & 3.75 & 0.06 & 0.01 & 0.92 & 2.28 & 0.14 \\
\hline Zone & 3 & 0.47 & 0.70 & 1.52 & 0.93 & 8.94 & 0.0001 & 0.09 & 0.97 & 2.78 & 0.05 \\
\hline Year*zone & 4 & 0.75 & 0.53 & 1.45 & 0.24 & 2.52 & 0.07 & 0.23 & 0.87 & 4.66 & 0.006 \\
\hline Cropsys (zone) & 18 & 0.44 & 0.97 & 1.52 & 0.12 & 0.80 & 0.70 & 0.24 & 0.99 & 4.39 & 0.0001 \\
\hline $\begin{array}{l}\text { Year*cropsys } \\
\text { (zone) }\end{array}$ & 3 & 0.35 & 0.79 & 0.27 & 0.85 & 2.37 & 0.08 & 0.13 & 0.94 & 0.07 & 0.98 \\
\hline
\end{tabular}

y Mean CFU was log transformed for general linear model (GLM) analysis.

${ }^{\mathrm{z}}$ Percent data were arcsine square root transformed for GLM analysis.

Table 4. Analysis of differences among agroecological zones for soil pH, CFU of Aspergillus section Flavi in soils, percent Aspergillus spp., and S and L strain isolates of $A$. flavus (LSD, $\alpha=0.05)^{t}$

\begin{tabular}{|c|c|c|c|c|c|c|c|c|c|c|}
\hline Zone $^{\text {u }}$ & $\mathbf{N}^{\mathbf{v}}$ & Rainfall $^{w}$ & $\operatorname{Temp}^{\mathbf{x}}$ & pH & CFU $^{y}$ & $\% \mathbf{A f}^{\mathbf{z}}$ & $\% \mathbf{A t}^{\mathbf{z}}$ & $\% \mathbf{A p} \mathbf{p}^{\mathbf{z}}$ & $\% \mathbf{L}^{\mathbf{z}}$ & $\% \mathbf{S}^{\mathbf{z}}$ \\
\hline SS & 15 & 900 & $45^{\circ} \mathrm{C}$ & $6.55 \mathrm{~b}$ & $65.1 \mathrm{~b}$ & 91 & 7 & 2 & $31 \mathrm{~b}$ & $60 \mathrm{c}$ \\
\hline NGS & 21 & 1,100 & $40^{\circ} \mathrm{C}$ & $6.82 \mathrm{ab}$ & $106.2 \mathrm{ab}$ & 92 & 7 & 1 & $47 \mathrm{~b}$ & $40 \mathrm{~b}$ \\
\hline SGS & 29 & 1,300 & $38^{\circ} \mathrm{C}$ & $7.22 \mathrm{a}$ & $222.9 \mathrm{a}$ & 91 & 6 & 3 & $89 \mathrm{a}$ & $2 \mathrm{a}$ \\
\hline $\mathrm{CS}$ & 22 & 1,500 & $35^{\circ} \mathrm{C}$ & $6.98 \mathrm{a}$ & $90.2 \mathrm{ab}$ & 91 & 6 & 3 & $88 \mathrm{a}$ & $3 a$ \\
\hline MSE & & & & 0.36 & 0.51 & 0.07 & 0.05 & 0.03 & 0.13 & 0.11 \\
\hline
\end{tabular}

${ }^{\mathrm{t}}$ All \% data were arcsine transformed for analysis; means within a column followed by a different letter are significantly different.

${ }^{\mathrm{u}} \mathrm{CS}=$ coastal, $\mathrm{SGS}=$ southern Guinea, $\mathrm{NGS}=$ northern Guinea, and SS = Sudan savannas.

${ }^{\mathrm{v}} \mathrm{N}=$ number of fields.

${ }^{\mathrm{w}}$ Rainfall maxima in $\mathrm{cm} /$ year.

${ }^{x}$ Temperature maxima in ${ }^{\circ} \mathrm{C} /$ year.

${ }^{\mathrm{y}} \mathrm{CFU}=$ back transformed from $\log _{10}$ (mean CFU/zone).

$\mathrm{z} \% \mathrm{Af}=$ mean $\%$ Aspergillus flavus $; \% \mathrm{At}=$ mean $\%$ A. tamarii $\% \mathrm{Ap}=$ mean $\%$ A. parasiticus $; \% \mathrm{~L}=$ mean $\%$ A. flavus $\mathrm{L}$ strains $;$ and $\% \mathrm{~S}=$ mean $\%$ A. flavus $\mathrm{S}$ strains isolated from the soil community.

Table 5. Correlations ${ }^{\mathrm{x}}$ of percent $\mathrm{S}$ and $\mathrm{L}$ strain isolates of Aspergillus flavus, percent A. parasiticus (APAR) and A. tamarii (ATAM) in the field ${ }^{\mathrm{y}}$, total $\mathrm{CFU}^{\mathrm{z}}$ isolates per $\mathrm{g}$ of soil, relative to soil $\mathrm{pH}$, latitude (LAT), and longitude (LON), $\mathrm{N}=79$

\begin{tabular}{lccccccc}
\hline & Soil $\mathbf{~ P H}$ & LAT & LON & \% & \%L & \%ATAM & \%APAR \\
\hline Soil pH & 1.00 & & & & & & \\
LAT & $-0.29^{* *}$ & 1.00 & & & & & \\
LON & -0.05 & 0.22 & 1.00 & & & & \\
\%S & 0.16 & $0.62^{* * *}$ & -0.03 & 1.00 & & & \\
\%L & $-0.22^{*}$ & $-0.57^{* * *}$ & -0.05 & $-0.88^{* * *}$ & 1.00 & & \\
\%ATAM & 0.15 & 0.05 & -0.03 & -0.13 & -0.26 & 1.00 & 1.00 \\
\%APAR & -0.02 & -0.09 & 0.00 & -0.09 & -0.14 & 0.01 & 0.09 \\
CFU & 0.09 & -0.19 & -0.07 & -0.14 & 0.09 & -0.09 & 1.00 \\
\hline
\end{tabular}

${ }^{\mathrm{x}}$ Correlation coefficients significant with $P<0.001=* * *, 0.01 \geq P>0.001=* *, 0.05 \geq P>0.01=*$.

y All \% data were arcsine square root transformed prior to analysis.

${ }^{\mathrm{z}} \mathrm{CFU}$ data were $\log _{10}$ (count+1) transformed. 
$(10,18,19,26)$. The aflatoxin producing potential of Aspergillus communities is higher when $\mathrm{S}$ strain is present, as $\mathrm{L}$ strain isolates produce on average only $33 \%$ as much toxin as $\mathrm{S}$ strain isolates (10). All North American $\mathrm{S}$ strain isolates express the $S_{B}$ phenotype and produce no $G$ aflatoxins $(10,17)$. In West Africa, $S$ strain isolates similarly produce greater quantities of aflatoxins than L strain isolates. By contrast, in the current study and as previously reported (11), the West African $S$ strain isolates all express the $\mathrm{S}_{\mathrm{BG}}$ phenotype producing both $\mathrm{B}$ and $\mathrm{G}$ aflatoxins. Certain regions in the United States have high incidences of $A$. parasiticus, and in those regions, contamination of crops with $\mathrm{G}$ aflatoxins may be reliably attributed to A. parasiticus (10). However, from results of the current study, it is more likely that crop contamination with $G$ aflatoxins in north Bénin is caused by the $\mathrm{S}$ strain of $A$. flavus.

The high aflatoxin producing potential of African S strain isolates, along with their dominance within fungal communities in parts of Bénin, suggest this strain may play an important role in contamination of foods in West Africa. In vitro and in vivo inoculation studies have shown that maize can be infected by West African $S$ strain isolates, and both $\mathrm{B}$ and $\mathrm{G}$ aflatoxins are expressed in maize (6). Nevertheless, it is not known whether the A. flavus S strain readily infects maize in the field under normal management conditions. Out of 227 aflatoxin-positive maize samples from Bénin analyzed at IITA in 1993 through 1995 , only 7 were positive for $G$ aflatoxins (14), 6 being from the far northern Sudan savanna and 1 being from the northern Guinea savanna. The current survey suggests that these $\mathrm{G}$ toxin-containing samples were more likely to have been contaminated, not by $A$. parasiticus, but by $\mathrm{S}_{\mathrm{BG}}$ isolates of A. flavus. The relative virulence of these strains to maize needs to be examined.

The A. flavus communities resident in different regions of Bénin differed in strain composition. The $\mathrm{L}$ strain isolates, although present throughout Bénin, were more prevalent in the south, while S strain isolates were found more frequently in the north. Thus, this study revealed that in addition to climatic and crop system variables influencing crop contamination, there is a gradient in the inherent toxigenicity of the endemic Aspergillus communities also influencing the aflatoxin content of crops in Bénin. Orum et al. (23) disassociated crop sequence from variations in the incidence of $\mathrm{S}$ strain isolates in Arizona and postulated that temperature variation has a greater impact on A. flavus community composition. In that study, the incidence of $\mathrm{S}$ strain isolates peaked during the warmest periods and rapidly declined during cool periods. This agrees with results from the current study, where the $\mathrm{S}$ strain isolates were most prevalent in the agroecological zones bordering the Sahara desert where the highest average temperatures occur. High incidences of $\mathrm{S}$ strain isolates are also frequently found in relatively low rainfall, high temperature regions of North America $(8,17,22)$. Production of many small sclerotia may be a survival trait for an organism adapted to rapid and extreme fluctuations in moisture and temperature. Such fluctuations are routine on the edges of deserts.

Geographical divergence among communities of section Flavi has been described in North America $(10,17,22)$, with resident section Flavi communities differing among regions in incidences of both $A$. tamarii and the $\mathrm{S}$ strain of A. flavus. In North America, S strain isolates were most common in alkali soils and rare in acidic soils. The relationship between soil $\mathrm{pH}$ and $\mathrm{S}$ strain isolates incidence in Bénin was opposite this and may be an additional reflection of physiological differences between North American and Beninese S strain isolates. Nevertheless, the inverse correlation between frequencies of the $\mathrm{L}$ strain isolates and $\mathrm{pH}$ was statistically weak and there was no significant correlation of $\mathrm{pH}$ with frequency of $\mathrm{S}$ strain, while the effect of zone/latitude on both strains was highly significant. Another interpretation is that soil $\mathrm{pH}$ may have nothing to do with A. flavus population dynamics and that climate is a more important determinant.

The severity of aflatoxin contamination of maize may more closely relate to the aflatoxin producing potential of the resident fungi infecting the crop than to the quantity of infections. This may partly explain the lack of correlation between aflatoxin content and kernel infection in Bénin $(15,27,28)$. Lack of correlation between frequencies of $\mathrm{L}$ strain isolates and aflatoxin production in mixed strain infections in cotton has been reported (9).

The climatic gradient across agroecological zones from very wet, 9month bimodal rainfall distribution in the south to semiarid 3-month rain distribution in the north provides a range of biophysical conditions in which aflatoxin contamination of grain may occur. Nevertheless, the risk of encountering aflatoxins in grain is not directly related to climatic variables (15). Management factors also contribute to risk of contamination, and crop management practices are zone specific $(14,15,28,31)$. Variability in the average aflatoxin producing potential of communities of fungi in Aspergillus section Flavi is documented (10) and clearly a factor contributing to variability in aflatoxin contamination of maize across Bénin (15). Different management practices may be required to reduce contamination caused by the various $A$. flavus morphotypes. Understanding factors influencing patterns of A. flavus strain composition may help in the assessment of the risk of aflatoxin contamination on a pan-regional scale.

\section{ACKNOWLEDGMENTS}

This work was supported in part by the BMZ (German Ministry of Co-operation), Germany, and by Specific Cooperative Agreement no. 58-64357-F054 with the Foreign Agricultural Service, U.S Department of Agriculture. We thank M. Sétamou, D. Downey, N. Hurban, E. Tedihou, and M. Koubé for technical assistance. This is IITA MS no. 99/021/JA.

\section{LITERATURE CITED}

1. Adebajo, L. O., Idowu, A. A., and Adesanya, O. O. 1994. Mycoflora and mycotoxins production in Nigerian corn and corn-based snacks. Mycopathologia 126:183-192.

2. Adhikari, M., Ramjee, G., and Berjak, P. 1994. Aflatoxin, Kwashiorkor, and Morbidity. Natural Toxins 2:1-3.

3. Bayman, P., and Cotty, P. J. 1993. Genetic diversity in Aspergillus flavus: Association with aflatoxin production and morphology. Can. J. Bot. 71:23-34.

4. Beardall, J., and Miller, J. D. 1994. Natural occurrence of mycotoxins other than aflatoxin in Africa, Asia, and South America. Mycotoxin Res. 10:21-40.

5. Brown, R., Cotty, P. J., and Cleveland, T. E. 1991. Reduction in aflatoxin content of maize by atoxigenic strains of Aspergillus flavus. J. Food Prot. 54:623-626.

6. Cardwell, K. F., and Cotty, P. J. 2000. Interactions among US and African Aspergillus spp. strains: Influence on aflatoxin production Phytopathology 90:S11.

7. Cotty, P. J. 1989. Virulence and cultural characteristics of two Aspergillus flavus strains pathogenic on cotton. Phytopathology 79:808-814.

8. Cotty, P. J. 1994. Comparison of four media for the isolation of Aspergillus flavus group fungi. Mycopathologia 125:157-162.

9. Cotty, P. J. 1994. Influence of field application of an atoxigenic strain of Aspergillus flavus on the populations of A. flavus infecting cotton bolls and on the aflatoxin content of cottonseed. Phytopathology 84:1270-1277.

10. Cotty, P. J. 1997. Aflatoxin-producing potential of communities of Aspergillus section Flavi from cotton producing areas in the United States. Mycological Res. 101:698-704.

11. Cotty, P. J., and Cardwell, K. F. 1999. Divergence of West African and North American Communities of Aspergillus section Flavi. Appl. Environ. Microbiol. 65:2264-2266.

12. Dorner, J. W., Cole, R. J., and Blankenship, P. D. 1992. Use of a biocompetitive agent to control preharvest aflatoxin in drought stressed peanuts. J. Food Prot. 55:88-89.

13. Egel, D. S., Cotty, P. J., and Elias, K. S. 1994. Relationships among isolates of Aspergillus sect. flavi that vary in aflatoxin production. Phytopathology 84:906-912.

14. Hell, K. 1998. Distribution and incidence of Aspergillus spp. in maize in Bénin and resultant contamination of maize grains by aflatoxin compounds in relation with agroecological zones. Ph.D. diss. Universität Hannover.

15. Hell, K., Cardwell, K. F., Sétamou, M., and Poehling, H.-M. 2000. Maize storage practices and their influence on aflatoxin contamination in stored grains in four agroecological zones in Bénin, West-Africa. J. Stored Prod. Res. 36:365-382.

16. Hesseltine, C. W., Shotwell, O., Smith, M., Ellis, J. J., Vandegraft, E., and Shannon, G. 1970. Production of various aflatoxins by strains of the Aspergillus flavus series. Pages 202-210 in: Proc. U.S.-Japan Conference on Toxic Microorganisms, 1st. M. Herzberg, ed. 
U.S. Government Printing Office, Washington, DC.

17. Horn, B. W., and Dorner, J. W. 1999. Regional differences in production of Aflatoxin $\mathrm{B}_{1}$ and cyclopiazonic acid by soil isolates of Aspergillus flavus along a transect within the United States. Appl. Environ. Microbiol. 65:1444-1449.

18. Joffe, A. Z. 1969. Aflatoxin produced by 1,626 isolates of Aspergillus flavus from groundnut kernels and soils in Israel. Nature 221:492-493.

19. Lisker, J., Michaeli, R., and Frank, Z. R. 1993. Mycotoxigenic potential of Aspergillus flavus strains isolated from groundnuts growing in Israel. Mycopathologia 122:177-183.

20. Mateles, R. I., and Adye, J. C. 1965. Production of aflatoxins in submerged culture. Appl. Microbiol. 13:208-211.

21. ONC/GTZ. 1992. Impact des politiques agricoles du Niger, du Nigeria, et du Togo sur la sécurité alimentaire du Bénin. LARES-SARL, B. P 08-0592, Cotonou, Bénin.

22. Orum, T. V., Bigelow, D. M., Cotty, P. J., and Nelson, M. R. 1999. Using predictions based on geostatistics to monitor trends in Aspergil- lus flavus strain composition. Phytopathology 89:761-769.

23. Orum, T. V., Bigelow, D. M., Nelson, M. R., Howell, D. R., and Cotty, P. J. 1997. Spatial and temporal patterns of Aspergillus flavus strain composition and propagule density in Yuma County, Arizona, soils. Plant Dis. 81:911-916.

24. Pons, W. A., Jr. 1969. Collaborative study on the determination of aflatoxins in cotton seed products. J. Assoc. Official Analytical Chem. 51:61-72.

25. Saito, M., Tsuruta, O., Siriacha, P., Kawasugi, S., Manage, M., and Buangsuwon, D. 1986. Distribution and aflatoxin productivity of the atypical strains of Aspergillus flavus isolated from soils in Thailand. Proc. Japanese Assoc. Mycotoxicol. 24:41.

26. Schroeder, H. W., and Boller, R. A. 1973. Aflatoxin production by species and strains of the Aspergillus flavus group isolated from field crops. Appl. Microbiol. 25:885-889.

27. Sétamou, M., Cardwell, K. F., Schulthess, F., and Hell, K. 1997. Aspergillus flavus infection and aflatoxin contamination of preharvest maize in Bénin. Plant Dis. 81:1323-1327.
28. Sétamou, M., Cardwell, K. F., Schulthess, F., and Hell, K. 1998. Effect of insect damage to maize ears, with special reference to Mussidia nigrivenella (Lepidoptera; Pyralidae), on Aspergillus flavus (Deuteromycetes; Monoliales) infection and aflatoxin production in maize before harvest in the Republic of Bénin. J. Econ. Entomol. 91:433-438.

29. Stoloff, L., and Scott, P. M. 1984. Natural poisons. Pages 477-500 in: Official Methods of Analysis of the Association of Official Analytical Chemists Association Inc. S. Williams, ed. Arlington, VA.

30. Udoh, J. M. 1996. Aflatoxin content of maize grains as affected by agricultural practices in five agroecological zones of Nigeria. Ph.D. diss. IITA, Ibadan, Nigeria.

31. Udoh, J. M., Ikotun, T. O., and Cardwell, K. F. 2000. Storage structures and aflatoxin content of maize in five agroecological zones of Nigeria. J. Stored Prod. Res. 36:187-201.

32. Wild, C. P., Jiang, Y.-Z., Allen, S. J., Jansen, L. A. M., Hall, A. J., and Montesano, R. 1990. Aflatoxin-albumin adducts in human sera from different regions of the world. Carcinogenesis 11:2271-2274. 